Fecha de recepción: junio 2020 Fecha de aceptación: agosto 2020 Versión final: septiembre 2020

\section{Ações Estratégicas para Translação de Conhecimento entre Academia e Sociedade: um estudo de caso no âmbito do PPGDesign da Univille} João E. C. Sobral ${ }^{(1)}$, Marli T. Everling ${ }^{(2)}$, Anna L. M. S. Cavalcanti ${ }^{(1)}$ e Rafaela Rodrigues ${ }^{(1)}$

Resumo: O conceito de democracia prevê um sistema igualitário de ingresso aos instrumentos de determinação política, e a realização deste ideal passa inevitavelmente pelos processos educacionais como forma garantidora do acesso às dimensões básicas, quais sejam, as econômicas, sociais e culturais. A educação mostra-se, no contexto democrático, como um dos mais poderosos meios de construção e garantia das relações facilitadoras deste processo. Diante do exposto, objetiva-se apresentar ações estratégicas para translação de conhecimento entre a academia e sociedade como forma de atuação edificadora do acesso aos processos democráticos por meio do desenvolvimento socioeconômico, realizadas pelo Programa de Pós-Graduação em Design da Universidade da Região de Joinville - PPGDesign/Univille. Para isso, foram revisados relatórios anuais produzidos pelo programa, bem como atividades associadas e constituídas em virtude deste compromisso. As considerações finais apresentam conclusões relacionadas a ações do PPGDesign/Univille, considerando a vocação dos programas profissionais, bem como o modo como se efetiva a translação do conhecimento entre academia e sociedade.

Palavras chave: Pós-Graduação - translação do conhecimento - pesquisa aplicada.

[Resumos em espanhol e inglês nas páginas 99-100]

${ }^{(1)}$ Investigador e Docente do Programa de Pós-Graduação em Design da Universidade da Região de Joinville, SC, Brasil. Coordenador do Grupo de Pesquisa ÍRIS.

(2) Investigadora e Docente do Programa de Pós-Graduação em Design da Universidade da Região de Joinville, SC, Brasil. Coordenadora do Grupo de Pesquisa ETHOS.

${ }^{(3)}$ Investigadora e Docente do Programa de Pós-Graduação em Design da Universidade da Região de Joinville, SC, Brasil. Coordenadora do Grupo de Pesquisa RE-CRIAR.

(4) Arquiteta e mestranda do Programa de Pós-Graduação em Design da Universidade da Região de Joinville, SC, Brasil. Participante do Grupo de Pesquisa ETHOS. 


\section{Translação de Conhecimento entre o PPGDesign da Univille, seu contexto e sua conexão com a democracia}

Quando olhamos para a cultura material, ideacional e comportamental constituída, frequentemente consideramos que estas construções constituem-se em avanços, incrementos e tomamos sua continuidade por garantido, ignorando que são acordos, narrativas ou ficções socialmente constituídas, cujo consenso é pendular e cuja manutenção precisa ser continuamente calibrada, nutrida e cuidada.

A educação, em um sistema democrático, deve ser promotora do acesso aos instrumentos de potência política, bem como a compreensão dos aspectos subjetivos (estado-da-arte) e objetivos (estado-da-técnica) envolvidos na constituição de comportamentos, ideais, e sistemas de artefatos e serviços que dão suporte ao nosso cotidiano pessoal, social, profissional, bem como a dimensão cidadã, seja em uma atuação local ou global, considerando um cenário tão complexo que inclui, entre outros desafios, a sustentabilidade da vida.

O Programa de Pós-Graduação em Design da Univille/PPGDesign, possui como área de concentração 'Design e Sustentabilidade', o que contribui para situar estas discussões como pano de fundo e conteúdo transversal da sua atuação tecnológica e científica, bem como na abordagem das disciplinas. Considera-se a capacitação docente, no âmbito do PPGDesign/Univille, como estratégia de democratização do conhecimento. Perspectiva semelhante, orienta as ações de translação do conhecimento para os setores público, social e indústria/serviços. A opção por atuar nestas três dimensões derivou do entendimento que o diferencial dos programas profissionais é contribuir com o avanço da pesquisa (aplicada, estratégica e tecnológica), comprometida com o contexto e o entorno no qual o programa está inserido. Atuar também nas dimensões pública e social, constitui-se em ação para que o conhecimento gerado seja democratizado, retornando para todos os cidadãos (e não apenas para a indústria e serviços), potencializando o incremento das dimensões básicas, quais sejam, as econômicas, sociais e culturais. Paralelamente, considera-se que as ações estratégicas para translação de conhecimento entre a academia e a sociedade constituemse em atuação edificadora e de democratização do desenvolvimento econômico.

Paulo Freire (1996) defende que no processo educacional que se reconhece como democrático, o conhecimento não pode ser transferido, bem como, acredita que a aprendizagem requer que os estudantes sejam sujeitos e artífices da construção do conhecimento. Considera também que uma sociedade mais solidária, em termos sociais e políticos, será possibilitada pela educação, e valoriza a reciprocidade entre mãos e mente como elo transformador das criações imaginadas em existência inventada, e transformação (ao invés de adaptação) da realidade, constituindo-se, dependendo da perspectiva criativa assumida, em atitude política e ética; podemos, assim, transformar o que está posto, considerando que 'estamos no mundo', 'estamos com o mundo' e 'estamos com os outros', na expressão heideggeriana do 'Daisen' ou o 'ser-no-mundo’ que com, e, por meio do outro se constrói. Freire reafirmava a esperança no há de vir humano, por acreditar na possibilidade de intervir no mundo 'como está' e aproximá-lo do que 'pode ser', ainda que as condições dadas decorram de fatores materiais, econômicos, políticos, culturais e ideológicos, e, portanto, de difícil superação. No mesmo sentido da facticidade humana, Sartre posiciona o ser humano condenado a ser livre e “...responsável pelo mundo e por si mesmo enquanto 
maneira de ser" (2014, p. 678). O ser humano, lançado ao mundo e construtor do meio cultural em que vive, se move como agente moral que faz para se fazer, pois é neste fazer que constrói a si e o mundo. A existência, assim entendida, é caracterizada pela liberdade, por opções e decisões.

Victor Margolin, em 'A Política do Artificial' (2014, p. 11) defende o design “como um meio de intenções e interpretações humanas sobre o que o 'mundo é' e o que 'pode ser'. Para $\mathrm{o}$ autor "em um mundo ideal em que todos os projetos melhorassem a vida, o ambiente sensível sustentaria a atividade humana produtiva, tanto como meio de comunicação (design gráfico) quanto como ação (produtos materiais). O autor vê, na atuação do arquiteto e urbanista Jaime Lerner (no planejamento urbano da cidade de Curitiba), a criatividade como instrumento para melhorar a qualidade de vida da população e o posicionamento do design como serviço social. Leonardo Boff, na obra 'O cuidado necessário - na vida, na saúde, na educação, na ecologia, na ética e na espiritualidade’, publicado em 2012, situa a fantasia como propulsor da criação e da inovação (de um modo similar ao valor que Paulo Freire dá a utopia e a esperança como motor para a transformação da realidade) e considera a educação como ignição para despertá-la, para impulsionar novas conexões e para apropriação da autonomia. Boff valoriza o conhecimento assimilado por meio da vivência e da experiência, bem como dos saberes tradicionais e mesmo ancestrais ancoradas em práticas, percepções e interpretações nem sempre sistematizadas e explícitas, mas que tornam determinado grupo, ou pessoa, detentoras e especialistas do conhecimento, e não pesquisadores, cujo aprofundamento e proximidade ao campo nem sempre é tão visceral. Esta valorização do conhecimento inato é reconhecido por abordagens participativas do design (parte do escopo do PPGDesign/Univille), que situam o participante como especialista da sua experiência; estas abordagens, entretanto requerem senso ético para que sejam usadas, como defende Margolin, como instrumentos para transição do 'mundo é' para o que 'pode ser' (ou, na palavras de Freire, da intervenção no mundo 'como está' e aproximá-lo do que 'pode ser'), situando o design como um serviço social, instrumento para melhorar a qualidade de vida de todos, e não um instrumento de apropriação do conhecimento especializado das pessoas a serviço da ética de mercado.

Para Freire, a preparação científica e tecnológica, e por sua vez a capacitação profissional, não deve ser apartada da formação ética que, associada a compreensão e a liberdade, pressupõe olhar crítico no assumir riscos e responsabilidades que conduzem a autonomia individual, que pode ser colocada a serviço de criações coletivas 'com os outros' em uma atitude democrática e não autoritária. Ao discutir o ensinar como especificidade humana, Freire (1999, p. 126) é mais explícito e verbaliza:

...se a educação não pode tudo, alguma coisa fundamental a educação pode. Se a educação não é chave de transformações sociais, não é também simplesmente reprodutora da ideologia dominante. O que quero dizer é que a educação nem é uma força imbatível a serviço da transformação da sociedade, porque assim eu queira, nem tampouco é a perpetuação do Status quo, porque o dominante decrete. 
Sua fala reflete a importância política-pedagógica da atuação. Freire (1999, p. 147) argumenta, ainda, que se o progresso científico e tecnológico não estiver comprometido fundamentalmente

Com os interesses humanos, às necessidades da nossa existência, perde sua significação. A todo o avanço tecnológico haveria de corresponder o empenho real de resposta imediata a qualquer desafio que pusesse em risco a alegria de viver de homens e mulheres [...] não se trata de inibir a pesquisa e frear os avanços, mas pô-los a serviço dos seres humanos.

Em sua argumentação o uso de avanços tecnológicos impingindo sacrifícios a milhares de pessoas, explicita o quanto podemos transgredir a ética universal em favor de uma ética do mercado e do lucro.

Reforça-se, junto ao senso comum, uma ciência que age de forma objetiva e independente, produzida de forma neutra e caracterizada pelo conhecimento progressivo, cumulativo e linear com a função única de nos conduzir à avanços sociais livres de subjetividades individuais e políticas. A ciência no seu formato mais visível atualmente, qual seja, ligado em uma relação de interdependência com a tecnologia, sintetizada na sigla C\&T; como bem coloca Yanarico (2011), quando trata das conexões entre a construção da crítica tecnológica e da sociedade, ao afirmar que esta autonomia, neutralidade e imparcialidade que deveria prover benefícios sociais, deu lugar a uma política científica de 'laissez faire'.

Neste sentido, se faz necessário um posicionamento crítico que reafirme a liberdade existencial e a responsabilidade social, que nos permitam posicionamentos diante de situações que exijam escolhas valorativas, de modo a assumir o risco e a responsabilidade apontada por Freire; postura importante, tanto no processo de ensino, quanto no processo de aprendizagem, e não só no plano teórico, mas na prática, no agir comprometido com o mundo. A C\&T precisa ser pensada de forma contrária ao senso comum, observando a necessidade de colocá-la entre aspas, e que por tratar-se de uma atividade humana, não é privada de valores e subjetividades; como afirma Morin (1996) é preciso que a ciência pense a própria ciência em sua ambivalência e aventura; Yanarico (2011, p. 112) na tentativa de construir uma agenda tecnocientífica que produza, progressivamente, benefícios sociais, propõe:

[...] repensar o entendimento científico dos fenômenos; entender que as práticas científicas são plurais; a atividade científica deve ser desenvolvida por estratégias ou estilos de cada sociedade; a análise e a avaliação das teorias científicas devem ser feitas através dos valores cognitivos e não cognitivos e não por regras ou algoritmos; uma meta fundamental da ciência, dependendo do contexto das causas sociais, deve priorizar em produzir o bem-estar humano; a ciência não deve ser mais entendida como livre de valores, ao estilo da ciência moderna, senão impregnada de valores epistêmicos e práticos.

A concepção e as práticas do PPGDesign/Univille se alinham com os pressupostos apresentados à medida em que a concepção das disciplinas, das linhas de pesquisa, das práticas 
de pesquisa e da interação com o entorno no qual o programa está situado, ocorrem em processos ancorados em projetos, e são desenvolvidos a partir das percepções, leituras e repertório preliminar das equipes, por vezes interdisciplinares, que se constituem para responder aos desafios propostos. A solidariedade em termos políticos e sociais, bem como o compromisso com a transformação do entorno, evidenciam-se na concepção dos fundamentos do Programa que capacita para atuação não só para empresa e serviços, mas também para o contexto social e urbano. A reciprocidade entre mãos e mente como elo transformador e criador em uma atitude política e ética, se viabiliza pelo compromisso com a capacitação tecnológica, sem entretanto perder de perspectiva o compromisso ético com a sustentabilidade da vida, expresso na área de concentração do programa e que se constitui em conteúdo transversal a todas as atividades, desde as disciplinas, passando pelos projetos de final de curso até a proposta filosófica do programa, atividades dos professores e propostas de pesquisa técnico-científica dos estudantes.

Considerando o desafio de 'estar no mundo', 'estar com o mundo' e 'estar com os outros', numa atitude de diálogo em perspectivas horizontais e não autoritárias, o programa assume uma atitude democrática, tanto no relacionamento com os estudantes e com o meio em que se insere, quanto nas metodologias utilizadas, que apesar do compromisso com a capacitação profissional, privilegiam enfoques participativos, co-criativos, centrados no ser humano e centrados na vida. Essa orientação significa, também, o compromisso com a capacitação de um profissional ético que reconhece os limites da sua atuação, mas sabe que sua autonomia e sua liberdade de escolher e decidir está alinhada com riscos e responsabilidades; que, além de conexões econômicas, sabe que as perspectivas que assume enquanto projeta, também possuem implicações sociais e na vida das pessoas, e, que sua atuação pode, ou reproduzir ideologias postas, ou contribuir com a transformação; que deve considerar a sustentabilidade econômica das ações com as quais se envolve, mas sobretudo a ética universal e a sustentabilidade social e ambiental.

\section{Metodologia}

Para discutir as ações do PPGDesign/Univille visando a efetivação da vocação dos programas profissionais, bem como contribuir com a translação do conhecimento entre academia e ao entorno no qual está inserido, foram revisados relatórios anuais produzidos pelo programa, bem como atividades associadas e constituídas com este compromisso. Para sistematizar os procedimentos, as análises abrangem discussões referentes à: (i) contextualização do PPGDesign e do Contexto no qual está inserido; (ii) essências do Programa; (iii) disciplinas com maior ênfase na translação do conhecimento; (iv) atuação integrada entre os projetos de pesquisa dos autores: ÍRIS, RE-CRIAR e ETHOS; (v) atuação dos Projetos ÍRIS, RE-CRIAR e ETHOS na Capacitação profissional discente, democratização do conhecimento com as organizações de entorno. 


\section{Contextualização do PPGDesign e do Contexto no qual está inserido}

A caracterização da cidade de Joinville e região, contribuiu para a criação de um cenário favorável ao desenvolvimento de produtos e serviços, tanto com o setor de indústria e serviços, quanto com organizações públicas e sociais, criando condições para absorção de profissionais criativos e comprometidos com a produção do conhecimento técnico-científico e, sobretudo com o compromisso para a requalificação de profissionais já inseridos, considerando a exigências atuais em termos tecnológicos, aspectos relacionados à cultura (e suas dimensões ideacional, comportamental e material), particularidades sociais, e, especialmente desafios alusivos a complexidade das relações de produção (em termos de cenário local e global) e a sustentabilidade.

Joinville, município com a maior população do estado de Santa Catarina, na região sul do Brasil, conta com a estimativa de 577.077 habitantes e com produto interno bruto (PIB a preços correntes) equivalente a $\mathrm{R} \$ 25.599 .407,00$, ocupando a $30^{a}$ posição no ranking brasileiro. O índice de desenvolvimento humano municipal situa o município na $21^{\text {a }}$ posição do ranking nacional. A cidade possui o maior parque exportador do estado e é responsável por $20 \%$ das exportações catarinenses, com uma indústria atuante nas áreas de metalmecânica, plásticos, têxtil, madeireira, química, farmacêutica, tecnologia da informação, entre outras. Em virtude das mudanças previstas em relação aos processos e tecnologias industriais, o desafio da cidade é reorientar seu posicionamento de futuro (Joinville em dados -Promoção social, 2018; Joinville em dados- Características gerais, 2018).

Com a consciência que cabe ao ensino e à educação um papel fundamental na participação da criação de bases necessárias para esta transição e para o desenvolvimento sustentável da região norte catarinense, auxiliando os setores a se colocarem em um regime de constante aperfeiçoamento, em uma perspectiva de sustentabilidade econômica, social e ambiental, o PPGDesign tem focado na qualificação de recursos humanos do setor produtivo, social e público por acreditar que esta seja a melhor forma de enfrentar os novos desafios trazidos pelos múltiplos cenários econômicos regionais e mundiais anunciados pela competitividade e pelas mudanças no cenário tecnológico, das relações trabalhistas e de empregabilidade global. Isso posto, observou-se a oportunidade de atuar na qualificação e capacitação profissional, bem como na dinâmica da inovação regional.

Este cenário apresenta-se como uma oportunidade para que o PPGDesign se posicione como agente catalisador de transformações relacionadas a sustentabilidade da vida, por meio da qualificação e requalificação de profissionais inseridos neste cenário. Observa-se, no decurso de atuação do PPGDesign, a sensibilização profissional que ocorre com os estudantes, ao longo de dois anos de convivência, em relação à sustentabilidade, processos participativos, e modos próprios de pensar e sistematizar o conhecimento na área do design.

Com este foco, o PPGDesign da Univille, criado em 2012 e implantado em 2013, titulou 51 mestres; no decorrer do seu percurso tem cooperado com o setor produtivo, contribuindo com a qualificação de profissionais que atuam nas áreas industrial, social e pública, considerando o design de produtos, sistemas e serviços e sua conexão com a sustentabilidade. 


\section{Essências do Programa}

O PPGDesign/Univille tem realizado experimentações de atuação técnico-científica voltadas a estes objetivos, apesar do ensino brasileiro, em nível de stricto sensu, não apresentar diretrizes claras para os programas profissionais nesta área. A proposta pedagógica do programa tem sido construída com base em processos educativos direcionados à pesquisa aplicada, estratégica e tecnológica voltadas à contextos regionais e dirigidos aos cenários urbano, social e industrial, visando a qualificação de profissionais comprometidos com a sustentabilidade na produção técnico-científica dirigida ao conhecimento estratégico e aplicado no design de sistemas, produtos e serviços.

A partir do amadurecimento do Programa e das constantes ações relacionadas ao planejamento do curso, o mesmo foi reestruturado em 2016, com implantação em 2017. A intenção central foi fortalecer o alinhamento das atividades e articulações dos projetos com base na análise de conteúdo. O processo envolveu a análise das produções técnicocientíficas (2013-2016) da equipe docente e discente. A análise pautou-se em três perguntas básicas: O que estamos produzindo? Quem estamos qualificando? Quem são os nossos interlocutores? Estas questões originaram articulações relacionadas à produção acadêmica, ênfase da qualificação e interlocutores a partir do qual foi estruturado o DNA do curso. Estes estudos objetivaram verificar o alinhamento das competências dos professores e egressos, bem como a coerência da proposta do Programa com os seus principais interlocutores, e constituindo-se, assim, em justificativa central para a proposta de reestruturação. Considerou-se, também: (i) a natureza dinâmica e flexível do mestrado em design e suas relações com o contexto social e o setor produtivo; (ii) a atualização do corpo docente; (iii) o fortalecimento da aderência, considerando produtos, serviços, sustentabilidade (área de concentração), e palavras-chave da linha de pesquisa (Universidade da Região de Joinville, 2016)

Observou-se que o conteúdo transversal que permeia todas as ações do PPGDesign/Univille continua sendo a sustentabilidade. Uma das referências para a discussão de paradigmas do conhecimento é a obra 'A Visão Sistêmica da Vida - Uma Concepção Unificada e suas Implicações Filosóficas, Políticas, Sociais e Econômicas' da autoria de Fritjof Capra e Pier Luisi (2014, p. 13); os autores argumentam que "uma sociedade sustentável precisa ser planejada de maneira tal que seus modos de vida, suas atividades comerciais, sua economia, suas estruturas físicas e suas tecnologias não interfiram na capacidade inerente da natureza para sustentar a vida". Esta perspectiva é complementada pelas argumentações de Boff (2012) que distingue: enquanto a sustentabilidade se orienta pelos aspectos objetivos (meio-ambiente, economia, sociedade, gestão e distribuição de recursos), a concepção do cuidado é dirigida para aspectos mais subjetivos (associados a sustentabilidade) como valores, atitudes, espiritualidade e ética. Ao questionar 'onde ficou o cuidado? O autor analisa que as contribuições da crítica (associada a razão), da criatividade (decorrente da técnica) e da libertação (conectada com o amor aos oprimidos) devem ser preservadas como construto histórico. Ao conectar os princípios da crítica, da criatividade e da libertação com a educação, evidencia e expande os pilares para educação propostos por Delors (2000) para educação adequada ao século XXI: aprender a conhecer, aprender a fazer, aprender a ser, aprender a viver juntos e, aprender a cuidar (acrescentada por Boff, 2012). 
Identificamos nestes autores fundamentos e possibilidades de capacitação para situar o design em uma perspectiva de manutenção a vida, observando não apenas critérios objetivos (econômicos, técnicos, ambientais, inovação e gestão) mas princípios mais subjetivos (ética, comportamento, atitudes, filosofia, política, sociedade, cultura) relacionados ao cuidado. Ponderamos que, em virtude da inserção do Programa em um cenário essencialmente industrial, a translação de conhecimento e esforço coletivo em busca de alternativas é mais relevante ainda.

\section{Disciplinas com maior ênfase na translação do conhecimento}

De acordo com a proposta pedagógica do Programa e os relatórios Sucupira (anualmente remetidos a Coordenação de Aperfeiçoamento de Pessoal de Nível Superior/CAPES), as disciplinas são articuladas a partir de desafios propostos por setores vinculados ao contexto industrial/serviços, público e social. Os relatórios evidenciam que a metodologia é fortemente ancorada em práticas de parceria com organizações, resultando em um intenso relacionamento com o contexto no qual o PPGDesign está inserido. Como prática docente, é usual a presença de dois professores, o que foi articulado intencionalmente para favorecer abordagens diferenciadas e complementares do conteúdo. A oferta das disciplinas é preliminarmente discutida com a intenção de identificar pontos de conexão e convergência entre elas, para que possam ser planejadas atividades conjuntas, bem como a continuidade de ações que iniciam em uma disciplina e finalizam em outra, possibilitando a articulação de diversas visões no intuito de resolver problemas associados ao design e ao cenário social, público e do setor industrial/serviços do entorno ao PPGDesign.

Outra forma de dinamizar o processo de ensino e aprendizagem (bem como, a democratização e transferência de conhecimento) é o envolvimento de empresas -públicas, não governamentais ou privadas- nas disciplinas, permitindo aos mestrandos contato direto com profissionais e problematizações do entorno. Essa inserção se estende com visitas técnicas, desafios projetuais integrados entre empresa-academia, seminários e mesas-redondas. As atividades práticas desenvolvidas nas disciplinas contam, portanto, com o apoio do conhecimento e da tecnologia do setor produtivo (industrial, empresarial, social). Algumas disciplinas foram criadas para apoiar práticas de maior autonomia dos estudantes na elaboração recíproca do conhecimento com os setores público, social e produtivo; estas disciplinas são essencialmente voltadas para a capacitação da pesquisa técnico-científica conectada com sua opção pessoal de aprofundamento; são elas: 'Teoria e Pesquisa em Design', 'Seminários de Trabalhos de Conclusão de Curso' e 'Mobilidade Acadêmica'.

\section{'Teoria e Pesquisa em Design' e 'Seminários de Trabalhos de Conclusão de Curso'}

Ao revisar os relatórios Sucupira (2013-2017), observa-se que os seis anos de atuação do PPGDesign/Univille tem sido um tempo de experimentação, aprendizagem e ousadia para assumir riscos, priorizando a pesquisa aplicada, estratégica e tecnológica, mesmo que 
ainda não existam diretrizes tão claras para os programas profissionais ${ }^{1}$. Os Trabalhos de Conclusão de Curso são, habitualmente, conectados com desafios reais (oriundos do setor industrial/serviços, público e social), e carregam em sua natureza, o objetivo de repensar o fazer profissional, o desenvolvimento e a transferência de tecnologia, e, do conhecimento como estratégias de transformação. As possibilidades associadas ao trabalho de conclusão são: trabalhos técnicos, desenvolvimento de produtos, processos, relatórios técnicos, registros de propriedade intelectual, ações de inovação tecnológica, entre outros (entregues sob o formato de memorial descritivo, relatório técnico ou dissertação, dependendo do grau de aprofundamento teórico ou da ênfase na documentação do projeto desenvolvido).

De acordo com a proposta pedagógica, desde o início do PPGDesign, a abordagem temática, conceitual, metodológica e a problematização dos Trabalhos de Conclusão de Curso, tem sido apoiada pela disciplina de 'Teoria e Pesquisa em Design', oferecida no primeiro ano de ingresso do estudante. Por ocasião da oferta desta disciplina, cada estudante já iniciou as discussões com o seu orientador e a disciplina oferece, sobretudo, aporte técnico para a estruturação do projeto, informações relacionadas ao comitê de ética, requisitos relacionados ao documento de qualificação e ao documento final. Embora seja conduzida por dois professores, tradicionalmente conta com a participação de toda a equipe docente, especialmente no início da disciplina (para discutir questões conceituais relacionadas a proposta, resultados esperados e possíveis parceiros) e ao final (para acompanhar a apresentação dos pré-projetos e contribuir com sugestões e pareceres).

Para ampliar o compromisso de translação do conhecimento associado ao tema de pesquisa do estudante, em 2016, foi criada a disciplina 'Seminários de Trabalhos de Conclusão de Curso' que prevê créditos por meio de atividades como "workshops, palestras, publicações, capacitações profissionais entre outros” (PPGDesign, 2016). A partir das práticas conduzidas, foi notável o potencial percebido para alavancar a translação recíproca de conhecimento com as organizações de entorno ao Programa.

\section{Mobilidade Acadêmica como Estratégia de Intercâmbio, Inserção e Reciprocidade}

A disciplina de Mobilidade Acadêmica foi criada para estimular a inserção em organizações, visando o aprofundamento técnico/científico (por meio de intercâmbio em outras instituições educacionais ou centros de pesquisa, ou instituições do setor produtivo em âmbito nacional ou internacional) relacionada ao trabalho de conclusão em período.

\section{Ações e Atividades encadeadas pelos projetos de pesquisa dos autores: ÍRIS, RE- CRIAR e ETHOS}

Os fundamentos elencados articulam todas as ações do Programa (disciplinas, atuação técnico-científica, projetos de pesquisa e trabalhos de conclusão dos estudantes) com as linhas de pesquisa do Programa e dos Professores. Este encadeamento ocorre por meio dos 'Projetos Guarda-Chuva'² que visam dar esta coerência às ações do Programa. 
Cada membro da equipe docente do PPGDesign coordena um projeto no intuito de alinhar suas investigações técnicas científicas com as necessidades do Programa, das Disciplinas e dos processos de capacitação discente. Os coordenadores do Projeto ÍRIS, RECRIAR e ETHOS vem atuando em colaboração por afinidade (e complementaridade) de temáticas e abordagens.

\section{Projeto ÍRIS - A imagem fotográfica e as ferramentas de concepção e desenvolvimento de projetos de artefatos tridimensionais}

A proposta é coordenada pelo Prof. Dr. João Sobral e está vinculado as linhas de pesquisa e atuação técnico científica 1 e 2. Objetiva investigações relacionadas à imagem, como sistema simbólico, e os processos de concepção e desenvolvimento de artefatos no campo do design; visa, ainda, potencializar pesquisas teóricas e práticas sobre a cultura material e fabril, articular atividades junto com parceiros de pesquisa, e, avançar com a interdisciplinaridade entre a graduação, pós-graduação e setor produtivo.

Dentre as propostas conduzidas está o 'Estudo comparativo dos métodos de fabricação digital e da produção de imagens fotográficas adstritas ao contexto do artefato tridimensional nas dimensões da concepção, desenvolvimento e do ensino e aprendizagem do design', financiado com recursos do edital Universal/CNPq, cujo resultado foi uma patente de processo.

O projeto mantém ainda o grupo de estudo HOMERO 3D (em colaboração com o Projeto ETHOS e RE-CRIAR) que visa fomentar o debate, a discussão, a pesquisa e o desenvolvimento de projetos de design que exploram a tecnologia de impressão 3D como recurso educacional de pessoas cegas ou com baixa visão. Em artigos publicados no $15^{\circ}$ Congresso Internacional Ergodesign/USIHC (2015) e na Revista Cuadernos (2018), a equipe apresentou: (i) reflexões relacionadas a impressora 3D como potencializadora de ações comunicacionais e educacionais voltadas para pessoas cegas; (ii) discussões acerca do sentido tátil, da percepção e da cognição em uma perspectiva de aprendizagem inclusiva orientada para pessoas cegas, bem como as contribuições da impressão 3D na dinâmica do 'ver' com as mãos. Da mesma forma, o ÍRIS empreende pesquisas no projeto 'Magma' (em associação com o projeto RE-CRIAR e o PRISMA ${ }^{3}$ ) que visa o desenvolvimento processos de moldes de fundição junto à empresa metalúrgica IMAM.

\section{Projeto RE-CRIAR - As dimensões criativas do design para a sustentabilidade}

Coordenado pela Profa. MSc. Anna Cavalcanti, e vinculado a linha de pesquisa e atuação técnico-científica 2, visa investigar a influência do design no campo da sustentabilidade, e se propõe a fomentar e estudar os aspectos relevantes para o desenvolvimento de produtos e serviços sustentáveis em toda a cadeia de valor. As reflexões geradas pelas pesquisas teóricopráticas objetivam aplicações diretas em projetos de produtos e serviços que venham a ser convertidos para a sociedade por meio de parcerias com o setor produtivo, a academia e a comunidade. Atua coletivamente com os projetos ÍRIS (em ações relacionadas ao grupo de estudos Homero 3D), ETHOS e DESUS ${ }^{4}$ (na composição do grupo de estudos LECid). 
O LECid - Laboratório de Estudos da Cidade (registrado no CNPq), atua conjuntamente em diversas iniciativas com foco nas dimensões sustentáveis, desenvolvendo diversas atividades envolvendo o setor público, privado e a comunidade.

\section{Projeto ETHOS - Design \& Relações de Uso}

Coordenado pela Profa. Dra. Marli Teresinha Everling é vinculado a linha de pesquisa e atuação técnico-científica 1; visa fomentar ações e pesquisas técnico-científicas para o 'Design e relações de uso' respondendo a desafios oriundos de setores sociais, públicos e industrial/serviços. Seu nome 'ETHOS' visa comunicar que abordagens de design, além de serem centradas no humano, devem ser orientadas para a manutenção da vida, "sem perder a perspectiva que a realidade humana é construto histórico e social constituído a partir da teia de relações coletivas dos seres nos meios em que nascem e vivem; o objetivo foi redirecionar para a condução de ações e pesquisas técnico-científicas orientadas para o design e relações de uso, respondendo a desafios oriundos dos múltiplos cenários associados" (Everling, et al., 2019). Está vinculado aos Grupo de Estudos LECid e HOMERO 3D. Presta assessoria em aspectos relacionados ao Design participativo/Design for Change ao Instituto Caranguejo de Educação Ambiental e aos Projetos AmaViva e SempreViva ${ }^{5}$. Paralelamente foram realizadas ações relacionadas ao Design e relações de uso considerando participação, sistemas de aprendizagem, ambiente para moradores de rua, ambiente para usuários e voluntários do centro de valorização a vida, e, oficinas de transferência tecnológica com foco na colaboração.

\section{Atuação dos Projetos ÍRIS, RE-CRIAR e ETHOS na Capacitação profissional dis- cente, democratização do conhecimento com as organizações de entorno}

A partir dos temas associados à área de concentração (sustentabilidade) das linhas de pesquisa e atuação técnico-científica 1 (Processo de Produção e Design) e 2 (Produção Tecnológica e Sustentabilidade), da ênfase em produtos e serviços, da participação nos projetos 'guarda-chuva', do suporte das disciplinas de 'Teoria e Pesquisa em Design', 'Seminários de Trabalhos de Conclusão de Curso' e 'Seminários de Experiências Profissionais', o estudante vai desenhando com o orientador o seu percurso no Programa, bem como vivências de democratização de conhecimento que deseja conduzir. Com frequência, ao longo do amadurecimento da proposta, surgem oportunidades de atuação em parceria com organizações.

O quadro 2 elenca os Trabalhos de Conclusão de Curso conectados com o projeto İris, bem como os parceiros de cada trabalho e a conexão com a linha de pesquisa. 
Quadro 2: Projetos de TCC vinculados ao projeto ÍRIS.

\begin{tabular}{lll}
\hline $\begin{array}{l}\text { TRABALHOS DE CONCLUSÃo DE CURSO } \\
\text {-PROJETO íRIS }\end{array}$ & Campo/Parceiro & Linha \\
\hline $\begin{array}{l}\text { Design de Superfície: a valorização do Museu Nacional } \\
\text { do Mar por meio da criação de artefatos [autora: Irma } \\
\text { Haensch Pereira] }\end{array}$ & $\begin{array}{l}\text { Patrimônio } \\
\text { Museu do Mar }\end{array}$ & LPA_TC1 \\
\hline $\begin{array}{l}\text { Aparelho para Secagem de Instrumentos Cirúrgicos } \\
\text { [autor: Carlos Amorim] }\end{array}$ & Odontologia & LPA_TC1 \\
\hline $\begin{array}{l}\text { Design do Equipamento: Ng-tox para a Empresa } \\
\text { Ecobabitonga Tecnologia [autor: Jonathan Camargo] }\end{array}$ & Tecnologia & Ecobabitonga \\
\hline $\begin{array}{l}\text { Design, projeto e desenvolvimento de produto } \\
\text { para indústria de mobiliário Serflex [autora: Daniela } \\
\text { Bernardi]. }\end{array}$ & $\begin{array}{l}\text { Mobiliário } \\
\text { Serflex }\end{array}$ & LPA_TC1 \\
\hline $\begin{array}{l}\text { As Percepções do Olhar: a fotografia aplicada ao } \\
\text { estímulo do processo criativo [autora: Eloah Maria } \\
\text { Oliveira Acauan] }\end{array}$ & Fotografia & Educação Infantil \\
\hline $\begin{array}{l}\text { Turismo inclusivo: uma proposta de inserção social } \\
\text { dos cegos por meio da fotografia multissensorial }\end{array}$ & Educação inclusiva & LPA_TC2 \\
[autor: Jonas Porto] & & \\
\hline $\begin{array}{l}\text { Da Filosofia ao Design: Um Acorde Psicodélico } \\
\text { [autora: Fernanda Rios] }\end{array}$ & Filosofia & \\
\hline $\begin{array}{l}\text { A Inclusão De Pessoas Com Deficiência Visual No } \\
\text { Ambiente Digital: Uma Proposta Para A Empresa Soul } \\
\text { Marketing [autor: Willian Amphilóquio] }\end{array}$ & Educação inclusiva & LPA_TC1 \\
\hline
\end{tabular}

Fonte: Os autores, 2019.

Observa-se que os TCCS vinculados ao Projeto ÍRIS estão equilibradamente distribuídos entre as linhas de pesquisa 1 e 2 . Três projetos possuem ênfase educacional (duas de orientação inclusiva, e uma a partir da perspectiva infantil), todas relacionadas ao olhar (ou sua ausência ou limitação), evidenciando que os objetivos do projeto ÍRIS e do grupo de estudos Homero 3D estão ressoando junto aos discentes. A proposta de Design de Superfície desenvolvida em parceria com o Museu do Mar de São Francisco do Sul (Santa Catarina, Brasil) também evidencia conexão com conceitos relacionados a imagem. A proposta com abordagem filosófica de determinado momento da história do design, evidencia a flexibilidade para que fosse encontrado um elo de ligação entre os interesses da estudante (intensamente sensibilizada para esta questão) e o projeto ÍRIS, cuja perspectiva de abordagem da imagem parte da filosofia. 
Duas propostas possuem cunho tecnológico, uma com ênfase no meio ambiente (em parceria com a Empresa Ecobabitonga Tecnologia) e outra, em saúde (Aparelho para Secagem de Instrumentos Cirúrgicos).

O quadro 3 elenca os Trabalhos de Conclusão de Curso conectados com o projeto RECRIAR, bem como os parceiros de cada trabalho e a conexão com a linha de pesquisa.

Quadro 3: Projetos de TCC vinculados ao projeto RE-CRIAR.

\begin{tabular}{|c|c|c|}
\hline $\begin{array}{l}\text { TRABALHOS DE CONCLUSÃO DE CURSO } \\
\text { PROJETO RE-CRIAR }\end{array}$ & Campo/Parceiro & Linha \\
\hline $\begin{array}{l}\text { Ecodesign de bolsas: um projeto de Upcycling de } \\
\text { sacos de ráfia para comunidades artesãs da Região } \\
\text { de Blumenau, Santa Catarina. [autora: Edna Regina } \\
\text { Steinhauser] }\end{array}$ & $\begin{array}{l}\text { Resíduos } \\
\text { Artesãs da Região } \\
\text { de Blumenau }\end{array}$ & LPA_TC2 \\
\hline $\begin{array}{l}\text { Proposta de Design de Serviços para um Sistema de } \\
\text { acondicionamento e coleta de resíduos da construção } \\
\text { civil em pequenas obras [autor: Mateus Szomorovszky] }\end{array}$ & $\begin{array}{l}\text { Resíduos } \\
\text { Construção civil }\end{array}$ & LPA_TC2 \\
\hline $\begin{array}{l}\text { Tecnologia para Movimentação e Transferência de } \\
\text { Pessoas com Mobilidade Reduzida no Leito [autor: } \\
\text { Marcelo Alves] }\end{array}$ & Tecnologia assistiva & LPA_TC2 \\
\hline $\begin{array}{l}\text { Desenvolvimento de Brindes a partir do Reuso de } \\
\text { Materiais: uma Perspectiva Sustentável [autor: Ricardo } \\
\text { Steiner] }\end{array}$ & $\begin{array}{l}\text { Resíduos } \\
\text { Docol Metais Ltda }\end{array}$ & LPA_TC2 \\
\hline $\begin{array}{l}\text { Desenvolvimento de produtos a partir do reuso } \\
\text { de materiais metálicos descartados [autor: Sidnei } \\
\text { Zamberlan] }\end{array}$ & Resíduos & LPA_TC2 \\
\hline $\begin{array}{l}\text { Gestão do design para a sustentabilidade no terceiro } \\
\text { setor: uma proposta para a Rede Feminina de } \\
\text { Combate ao Câncer de Indaial [Caroline Haddlich] }\end{array}$ & $\begin{array}{l}\text { Resíduos } \\
\text { ONG Rede Feminina } \\
\text { de Combate ao } \\
\text { Câncer de Indaial6 }\end{array}$ & LPA_TC2 \\
\hline $\begin{array}{l}\text { Design de moda inclusivo: tecnologia vestível para } \\
\text { pessoas com autismo [autora: Carla Wick] }\end{array}$ & Tecnologia assistiva & LPA_TC2 \\
\hline
\end{tabular}

Fonte: Os autores, 2019.

Observa-se nos TCCS vinculados ao Projeto RE-CRIAR a, consistência de abordagem orientada para resíduos, upcycling, reaproveitamento e sustentabilidade em diversas áreas como moda, engenharia, arquitetura, publicidade e propaganda, contribuindo com a capacitação de recursos humanos (com ênfase na criatividade, no design e na sustentabilidade). 
As exceções foram os desafios relacionados a tecnologia de movimentação e transferência de pessoas com mobilidade reduzida no leito e ao design de moda inclusivo: tecnologia vestível para pessoas com autismo; este desvio enfatiza a entrega ao processo de pesquisa, acolhendo os resultados que vieram e que redirecionaram as investigações de uma direção para outra, evidenciando que o problema real da problematização anteriormente feita (sob uma perspectiva) era dependente de uma solução relacionada à tecnologia assistiva. $\mathrm{O}$ quadro 4 apresenta os projetos desenvolvidos por mestrandos vinculados ao projeto ETHOS, coordenado pela Professora Marli Everling.

Quadro 4: Projetos de TCC vinculados ao projeto ETHOS

\begin{tabular}{|c|c|c|}
\hline $\begin{array}{l}\text { TRABALHOS DE CONCLUSÃO DE CURSO } \\
\text { PROJETO ETHOS }\end{array}$ & Campo/Parceiros & Linha \\
\hline $\begin{array}{l}\text { Design de Embalagem de Alimento Congelado: Um } \\
\text { Estudo de Caso da Itálica Indústria e Comércio de } \\
\text { Alimentos Ltda. [autor: Luiz Eduardo Souza] }\end{array}$ & $\begin{array}{l}\text { Embalagens } \\
\text { Itálica Ltda. }\end{array}$ & LPA_TC1 \\
\hline $\begin{array}{l}\text { O Processo Criativo em Arquitetura e Design: } \\
\text { Afinidades e a Discussão da Identidade a } \\
\text { Metroquadrado [autor: Miguel Canãs Martins] }\end{array}$ & $\begin{array}{l}\text { Serviços } \\
\text { Escritório } \\
\text { Metroquadrado }\end{array}$ & LPA_TC1 \\
\hline $\begin{array}{l}\text { A Pesquisa Ação e o Design Participativo: } \\
\text { Sensibilidade e Empatia para Abordagem de Grupos } \\
\text { Sociais [autora: Maria Odete Duarte Stahn] }\end{array}$ & $\begin{array}{l}\text { Grupo Social Pontos } \\
\text { de Amor }\end{array}$ & LPA_TC2 \\
\hline $\begin{array}{l}\text { Design e Desenvolvimento de Produtos de Moda: } \\
\text { A Organização de uma Estrutura Projetual para as } \\
\text { Disciplinas de Projeto de Coleção do Curso Superior } \\
\text { de Tecnologia em Design de Moda do Senai/Curitiba } \\
\text { [autor Edson Korner] }\end{array}$ & $\begin{array}{l}\text { Educação } \\
\text { Senai Curitiba }\end{array}$ & LPA_TC1 \\
\hline $\begin{array}{l}\text { Princípios de Design Thinking e de Cenografia Teatral } \\
\text { Aplicados a um Processo Projetual de Design de } \\
\text { Interiores em Ambientes de Varejo [autora: Susane } \\
\text { Tomelin Raiter] }\end{array}$ & Educação & LPA_TC1 \\
\hline $\begin{array}{l}\text { Uma Perspectiva sobre a Atuação do Designer em } \\
\text { um Mundo Complexo, em uma Aplicação Prática } \\
\text { Denominada Rota do Mangue [autora: Morgana Creuz } \\
\text { Gasnke] }\end{array}$ & $\begin{array}{l}\text { Educação } \\
\text { Instituto Caranguejo } \\
\text { de Educação } \\
\text { Ambiental }\end{array}$ & LPA_TC1 \\
\hline $\begin{array}{l}\text { Criar, Desenhar e Modelar nos processos de Design de } \\
\text { Moda [autora: Mara Rúbia Theis] }\end{array}$ & Educação & LPA_TC2 \\
\hline $\begin{array}{l}\text { Design, abordagens participativas e hospitalização } \\
\text { infantil [autor: Leonardo Cecyn] }\end{array}$ & $\begin{array}{l}\text { Serviços } \\
\text { Hospital Infantil de } \\
\text { Joinville - HJAF }\end{array}$ & LPA_TC1 \\
\hline
\end{tabular}

continúa $>>$ 


\begin{tabular}{lll}
\hline Design, arquitetura e inovação social [autora: Rafaela & Serviços & LPA_TC1 \\
Rodrigues] & Administração \\
& Pública de Joinville \\
\hline
\end{tabular}

Fonte: Os autores, 2019

Os TCCS vinculados ao Projeto ETHOS são dirigidos para o setor industrial/serviços, setor público, social e educacional. Embora, a educação esteja identificada como setor específico, frequentemente se sobrepõem e se associa as outras três categorizações. Duas propostas foram orientadas para os setores industrial e serviços; a primeira delas, além de resultar em uma linha de embalagem de alimentos para a Indústria Itálica, também resultou em processo metodológico para embalagens com ênfase na sustentabilidade, no design da informação e em relações de uso. A segunda proposta, orientada para um escritório de arquitetura, teve dois desdobramentos: o desenvolvimento participativo de um processo metodológico para o escritório, bem como um novo empreendimento com ênfase em ações co-criativas.

Quatro outras propostas tiveram ênfase educacional e todas resultaram em processos educacionais: o primeiro, conduzido com o grupo 'Pontos de Amor', foi desenhado para ser adequado a grupos sociais; o segundo abrangeu a estrutura projetual das disciplinas de todos os períodos do tecnólogo em Moda do SENAI-Curitiba, bem como sua conexão com as demais disciplinas, e foi delineado, participativamente, com a equipe docente do curso sob a mediação do estudante de mestrado (que coordenava o Tecnólogo); o terceiro incorporou princípios de design thinking e cenografia para o desenvolvimento de um processo projetual para o design de interiores; o quarto resultou na síntese de conteúdo de aprendizagem (ilustrado e interativo) de suporte aos processo de criar, desenhar e modelar na área de moda. O conteúdo foi disponibilizado em formato on-line.

Os três últimos trabalhos orientados foram desenvolvidos em parceria com o Instituto Caranguejo de Educação Ambiental, Hospital Infantil de Joinville e setores da administração pública de Joinville. O trabalho desenvolvido com o instituto visava a proposição de um produto-sistema de apoio a um jogo que integra a vida analógica e digital no entorno da Baía da Babitonga (Joinville, SC, Brasil) denominado Rota do Mangue (com a intenção de promover a contemplação e o cuidado com a Baía). Com o Hospital Infantil de Joinville foi desenvolvido um processo participativo com a equipe multiprofissional da ala de 'Saúde Mental' no intuito de mediar a construção coletiva de uma tecnologia de suporte à prática profissional da equipe. Com a administração pública de Joinville, está em desenvolvimento um processo participativo de facilitação a participação popular em audiências públicas. 


\section{Considerações finais}

Partindo da premissa que em um sistema democrático a educação deve ser potencializadora da qualidade de vida, considera-se que a pós-graduação em design tem contribuições a oferecer nas dimensões da vida social, econômica, pública e profissional entre outras, bem como, na transformação do mundo 'como está' para como ele 'pode ser'. Tem também, contribuições em relação a reflexões sobre o equilíbrio entre o nosso fazer (considerando habilidades criativas, possibilidades e respostas decorrentes do avanço de conhecimentos sobre materiais e tecnologia) e as consequências desta atuação sobre a sustentabilidade do meio em que vivemos, da vida de outros seres e da nossa própria vida.

A educação (dependendo da configuração do sistema) se constitui em caminho para democratização de conhecimento e mesmo de mobilidade social, embora, neste artigo este não seja o ponto central. Pretendeu-se, ao longo dele, situar o design como instrumento e possibilidade de ampliar a democracia, visto que o design é reflexo e está ligado ao agir, e por vezes, amplifica comportamentos, crenças e valores que vagueiam em nossas mentes coletivas. Mas para isso, programas como o PPGDesign/Univille, precisam incluir discussões, análises e reflexões sobre a ética social, do cuidado e da sustentabilidade em seu fazer diário.

Observando as práticas e os resultados de capacitação dos Projetos ÍRIS, RE-CRIAR e ETHOS, evidencia-se a atenção para estas questões que necessitam, entretanto, ser continuamente amadurecidas, reafirmadas e fortalecidas para que possam ser amplificadas e fazer eco na transformação do cenário do qual o PPGDesign faz parte.

Como forma de democratizar e disseminar o conhecimento gerado, continuamente, são promovidos eventos, dentre os quais destacam-se o GAMPI Plural (com periodicidade anual), o $14^{\circ}$ Congresso Internacional Ergodesign/USIHC (2014), o $2^{\circ}$ Congresso Internacional $/ 8^{\circ}$ Workshop Design \& Materiais (2017) e o $13^{\circ}$ Congresso Brasileiro de Pesquisa e Desenvolvimento em Design - P\&D Design (2018); os eixos temáticos destes evento, foram estruturados, na sua essência, para comunicarem princípios relevantes para o PPGDesign e contribuir com a disseminação do conhecimento gerado no Programa. O periódico Plural Design (publicação técnico-científica, recentemente criada pelo PPGDesign) também intenciona disseminar a colaboração prática e teórica entre academia e sociedade para o desenvolvimento da ciência aplicada de impacto social.

Por fim, considera-se que estas ações não são ponto de chegada, mas um percurso de experimentação (em constante mutação, reconfiguração e aperfeiçoamento) para que o conhecimento gerado, de forma iterativa entre o PPGDesign e o cenário público, social, bem como, com o setor industrial/serviços de entorno, alcance a sociedade, efetivando a translação do conhecimento para amplificar benefícios.

\section{Notas}

1. Este esforço foi reconhecido no primeiro ciclo de avaliação da CAPES que destacou e avaliou como 'muito boa' as dimensões 'produção técnica' e a 'inserção social'. 
2. Os projetos guarda-chuva são de autoria de cada professor e estruturam a sua atuação técnico-científica, pesquisa, inserção social, disciplinas e orientações.

3. O projeto PRISMA é coordenado pelo professor Danilo Corrêa Silva e visa promover investigações e desenvolvimentos, de caráter tecnológico e acadêmico, relativos a novos materiais e suas aplicações no design de produtos (PPGDESIGN/UNIVILLE, WEB).

4. Coordenado pela Professora Adriane Shibata, visa promover ações de ensino, pesquisa e extensão em design, considerando a sustentabilidade, suas dimensões e a inovação social (PPGDESIGN/UNIVILLE, WEB).

5. Os projetos AmaViva e SempreViva são ações de capacitação para o trabalho e renda, especialmente com mulheres; a proposta é parte do Projeto guarda-chuva SIMBOL (coordenado pela Professora Elenir com vistas ao desenvolvimento de pesquisas em design, fundadas na antropologia cultural contemplando 'o design e suas fronteiras na instituição social da cultura simbólica').

6. Também contribuíram as confecções da região de Indaial, o Centro Universitário Leonardo da Vinci e a Fundação Indaialense de Cultura.

\section{Bibliografia}

Acauan, E. (2015). As Percepções do Olhar: Uma Análise da Linguagem Fotográfica em Crianças. Orientador: Prof. Dr. João Eduardo Chagas Sobral. Projeto Final Mestrado. Joinville: Univille.

Alves, M. (2016). Tecnologia para Movimentação e Transferência de Pessoas com Mobilidade Reduzida no Leito. Orientadora: Profa. MSc. Anna Luiza Moraes de Sá Cavalcanti. Projeto Final Mestrado. Joinville: Univille.

Amorin, C. (2015). Aparelho para Secagem de Instrumentos Cirúrgicos. Orientador: Prof. Dr. João Eduardo Chagas Sobral. Projeto Final Mestrado. Joinville: Univille.

Bernardi, D. (2016). Design, Projeto e Desenvolvimento de Produto para Indústria de Mobiliário Serflex. Orientador: Prof. Dr. João Eduardo Chagas Sobral. Projeto Final Mestrado. Joinville: Univille.

Boff, L. (2012). O Cuidado Necessário - Na Vida, na Saúde, na Educação, na Ecologia, na Ética e na Espiritualidade. Petrópolis: Vozes.

Camargo, J. (2016). Design do Equipamento NG-Tox para a Ecobabitonga Tecnologia. Orientador: Prof. Dr. João Eduardo Chagas Sobral. Projeto Final Mestrado. Joinville: Univille.

Capra, F.; Luisi, P., Pier. A. (2014). Visão Sistêmica da Vida: Uma Concepção Unificada e suas Implicações Filosóficas, Políticas, Sociais e Econômicas. São Paulo: Cultrix.

Cavalcanti, A. (2017). Projeto RE-CRIAR - As dimensões criativas do design para a sustentabilidade. Joinville: Univille. 2017.

Delors, J. (2000). et al. Educação: um tesouro a descobrir. Relatório para a UNESCO da Comissão Internacional sobre Educação para o século XXI. São Paulo: Cortez.

Everling, M. (2017). Projeto ETHOS - Design \& Relações de Uso. Joinville: Univille.

Freire, P. (1999). A Pedagogia da Autonomia - saberes necessários a prática educativa. $12^{\circ}$ impressão. São Paulo: Terra e Paz. 
Ganske, M. (2016). Design para Inovação Social: Uma Perspectiva sobre a Atuação do Designer em um Mundo Complexo, em uma Aplicação Prática Denominada Rota do Mangue. Orientadora: Profa. Dra. Marli Teresinha Everling. Projeto Final Mestrado. Joinville: Univille.

Hadlich, C. (2018). Gestão do Design para a Sustentabilidade no Terceiro Setor: Uma Proposta para a Rede Feminina de Combate ao Câncer de Indaial. Orientadora: Profa. Dra. Anna Luiza Moraes de Sá Cavalcanti. Projeto Final Mestrado. Joinville: Univille.

Heidegger, M. (2006). Ser e Tempo. Petrópolis, RJ.: Editora Vozes.

Korner, E. (2016). Design e Desenvolvimento de Produtos de Moda: A Organização de uma Estrutura Projetual para as Disciplinas de Projeto de Coleção do Curso Superior de Tecnologia em Design de Moda do Senai/Curitiba. Orientadora: Profa. Dra. Marli Teresinha Everling. Projeto Final Mestrado. Joinville: Univille.

Martins, M. (2015). O Processo Criativo em Arquitetura e Design: Afinidades e a Discussão da Identidade da Metroquadrado. Orientadora: Marli Teresinha Everling. Projeto Final Mestrado. Joinville: Univille.

Morin, E. (2013). Ciência com consciência. Rio de Janeiro: Bertrand Brasil.

Pereira, I. (2015). Design de Superfície: A Valorização do Museu Nacional do Mar por meio da Criação de Artefatos. Orientador: Prof. Dr. João Eduardo Chagas Sobral. Projeto Final Mestrado. Joinville: Univille.

Prefeitura Municipal de Joinville (2018). Joinville em Dados 2018 - Características Gerais. Joinville: Prefeitura Municipal de Joinville. Disponível em https://www.joinville.sc.gov.br/wpcontent/uploads/2018/09/Joinville-Cidade-em-Dados-2018-Caracter\%C3\%ADsticasGerais.pdf. Acesso em 03 fev. 2018.

Prefeitura Municipal de Joinville (2018). Joinville em Dados 2018 - Promoção Social. Joinville: Prefeitura Municipal de Joinville. Disponível em https://www.joinville.sc.gov.br/wp-con tent/uploads/2018/09/Joinville-Cidade-em-Dados-2018-Promo\%C3\%A7\%C3\%A3oSocial.pdf. Acesso em 03 fev. 2018.

Raiter, S. (2016). Princípios de Design Thinking e de Cenografia Teatral Aplicados a um Processo Projetual de Design de Interiores em Ambientes de Varejo. Orientadora: Profa. Dra. Marli Teresinha Everling. Projeto Final Mestrado. Joinville: Univille.

Rios, F. (2017). Da Filosofia ao Design: Um Acorde Psicodélico. Orientador: Prof. Dr. João Eduardo Chagas Sobral. Projeto Final Mestrado. Joinville: Univille. 2017.

Sartre, J. (2014). O ser e o nada. 23a ed. Petrópolis, RJ: Ed. Vozes, 2014.

Stahn, M. (2016). A Pesquisa Ação e o Design Participativo: Sensibilidade e Empatia para Abordagem em Grupos Sociais. Orientadora: Profa. Dra. Marli Teresinha Everling. Projeto Final Mestrado. Joinville: Univille..

Steiner, R. (2016). Desenvolvimento de Brinde a partir do Reuso de Materiais: Uma Perspectiva Sustentável. Orientadora: Profa. MSc. Anna Luiza Moraes de Sá Cavalcanti. Projeto Final Mestrado. Joinville: Univille.

Steinhauser, E. (2016). Ecodesign de Bolsas: Um Projeto de Upcycling de Sacos de Ráfia para Comunidades Artesãs da Região de Blumenau, Santa Catarina. Orientadora: Profa. MSc. Anna Luiza Moraes de Sá Cavalcanti. Projeto Final Mestrado. Joinville: Univille.

Sobral, J. (2020). "Projeto ÍRIS - A imagem fotográfica e as ferramentas de concepção e desenvolvimento de projetos de artefatos tridimensionais", em Revista Cuaderno 83 | Centro de Estudios en Diseño y Comunicación (2020). pp 179-192. 
Sobral, J.; Cavalcanti, A.; Everling, M. (2015). "Ver com as Mãos: A Tecnologia 3d Como Recurso Educativo Para Pessoas Cegas”, em Anais do $15^{\circ}$ Ergodesign \& Usihc, São Paulo: Blucher, 2015. p. 1327-1335.

Sobral, J.; Cavalcanti, A.; Everling, M. (2015). "Ver com as mãos e dar à luz um mundo: a Tecnologia 3D e suas possibilidades cognitivas para pessoas cegas”. pp. 179-192

Souza, L. (2015). Design de Embalagem de Alimento Congelado: Um Estudo de Caso da Itálica Indústria e Comércio de Alimentos Ltda. Orientadora: Marli Teresinha Everling. Projeto Final Mestrado. Joinville: Univille.

Szomorovszky, M. (2015). Proposta de Design de Serviços para um Sistema de Acondicionamento e Coleta de Resíduos da Construção Civil em Pequenas Obras. Orientadora: Profa. MSc. Anna Luiza Moraes de Sá Cavalcanti. Projeto Final Mestrado. Joinville: Univille.

Theis, M. (2018). Criar, desenhar e modelar - O desenvolvimento de conteúdo interativo para aprendizagem nos processos de design de moda. Orientadora: Profa. Dra. Marli Teresinha. Projeto Final Mestrado. Joinville: Univille.

Universidade da Região de Joinville (2016). Projeto de Reestruturação do Programa de Pós-Graduação em Design. Joinville: Univille.

Universidade da Região de Joinville (2014). Relatório Sucupira 2013. Joinville: Univille. Universidade da Região de Joinville (2015). Relatório Sucupira 2014. Joinville: Univille. Universidade da Região de Joinville (2016). Relatório Sucupira 2015. Joinville: Univille. Universidade da Região de Joinville (2017). Relatório Sucupira 2016. Joinville: Univille. Universidade da Região de Joinville (2018). Relatório Sucupira 2017. Joinville: Univille. Universidade da Região de Joinville (2019). Relatório Sucupira 2018. Joinville: Univille. Yanarico, A. (2011). "Uma tecnociência para o bem-estar social", em Ciência \& Tecnologia social - Revista do observatório do Movimento pela Tecnologia Social da América Latina, v.1, n.1, p. 99-120, jul. 2011.

Zamberlan, S. (2015). Desenvolvimento de Produtos a partir do Reuso de Materiais Metálicos Descartados. Orientadora: Profa. MSc: Anna Luiza Moraes de Sá Cavalcanti. Projeto Final Mestrado. Joinville: Univille.

Resumen: El concepto de democracia proporciona un sistema igualitario de entrada a los instrumentos de determinación política, y la realización de este ideal inevitablemente pasa por los procesos educativos como una forma de garantizar el acceso a dimensiones básicas: económicas, sociales y culturales. La educación se muestra, en el contexto democrático, como uno de los medios más poderosos para construir y garantizar las relaciones que facilitan este proceso. En vista de lo anterior, el objetivo es presentar acciones estratégicas para la traducción del conocimiento entre la academia y la sociedad como una forma de acción que construye el acceso a procesos democráticos a través del desarrollo socioeconómico, llevado a cabo por el Programa de Posgrado en Diseño de la Universidad de la Región de Joinville - PPGDesign / Univille. Con este fin, se revisaron los informes anuales producidos por el programa, así como las actividades asociadas y se constituyeron bajo este compromiso. Las consideraciones finales presentan conclusiones relacionadas 
con las acciones de PPGDesign / Univille, considerando la vocación de los programas profesionales, así como la forma en que se lleva a cabo la traducción del conocimiento entre la academia y la sociedad.

Palabra clave: Estudios de posgrado - traducción del conocimiento - investigación aplicada

\begin{abstract}
The concept of democracy provides an egalitarian system of entry to the instruments of political determination, and the realization of this ideal inevitably goes through educational processes as a way of guaranteeing access to basic dimensions: economic, social, and cultural. Education is shown, in the democratic context, as one of the most powerful means to build and guarantee the relationships that facilitate this process. In view of the above, this paper presents the strategic actions for the translation of knowledge between academia and society as a form of action that builds access to democratic processes through socioeconomic development, carried out by the Postgraduate Program in Design of the University of the Joinville Region - PPGDesign / Univille. To this goal, the annual reports produced by the program, as well as the associated activities, were reviewed and constituted under this commitment. The final considerations present conclusions related to the actions of PPGDesign / Univille, considering the vocation of professional programs, as well as the way in which the translation of knowledge is carried out between academia and society.
\end{abstract}

Keywords: Postgraduate studies - knowledge translation - applied research.

[Las traducciones de los abstracts fueron supervisadas por el autor de cada artículo] 